\title{
Numerical analysis of concrete-filled spiral welded stainless steel tubes subjected to compression
}

\author{
D. $\mathrm{Li}^{\mathrm{a} *}$, B. Uy ${ }^{\mathrm{a}}$, F. Aslani ${ }^{\mathrm{b}}$ and C. Hou

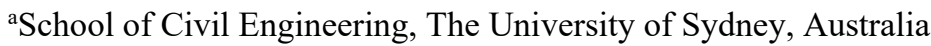 \\ ${ }^{b}$ School of Civil, Environmental and Mining Engineering, The University of Western Australia, Australia \\ *corresponding author, e-mail address: Dongxu.li@sydney.edu.au
}

\begin{abstract}
Spiral welded stainless tubes are produced by helical welding of a continuous strip of stainless steel. Recently, concrete-filled spiral welded stainless steel tubes have found increasing application in the construction industry due to their ease of fabrication and aesthetic appeal. However, an in-depth understanding of the behaviour of this type of structure is still needed due to the lack of proper design guidance and insufficient experimental verification. In this paper, the mechanical performance of concrete-filled spiral welded stainless steel tubes will be numerically investigated with a commercial finite element software package, through which an experimental program can be designed properly. Specifically, the proposed finite element models take into account the effects of material and geometric nonlinearities. Moreover, the initial imperfections of stainless steel tubes and the form of helical welding will be appropriately included. Enhancement of the understanding of the analysis results can be achieved by extending results through a series of parametric studies based on the developed finite element model. Thus, the effects of various design parameters will be further evaluated by using the developed finite element model. Furthermore, for the purposes of wide application of such types of structure, the accuracy of the behaviour prediction in terms of ultimate strength based on current design codes will be studied. The authors herein compared the load capacity between the finite element analysis results and the existing codes of practice.
\end{abstract}

Keywords: Concrete-filled columns; stainless steel; spiral welded; finite element analysis.

\section{Introduction}

In the current construction industry, welded steel tubes can be classified as longitudinal welded steel tubes and spiral welded tubes. Compared with longitudinal welded tubes, spiral welded tubes exhibit significant structural and economic benefits. Dimensions of longitudinal welded tubes largely depend on the size of the steel strip or plate, while different tube diameters can be manufactured from a single steel coil strip by utilising the spiral welding approach [1]. Moreover, the helical welding method can reduce $10-25 \%$ of the stress subjected to the welding itself [2], compared with longitudinal welded steel tubes. Relieve of stress on welding can subsequently increase the load resisting capacity of the steel tubes. In addition, the ease of fabrication allows the spiral welded steel tubes to be manufactured onsite [3].
Concrete-filled steel tubes (CFST) have been extensively used over the past few decades due to their improved performance over conventional reinforced concrete column types [4]. Significant research efforts have been conducted on these column types into the various design parameters for axial strength. Uy $[5,6]$, Han [7], Giakoumelis and Lam [8] and Liew and Xiong [9] reported extensive experimental programmes on short and slender CFST columns under axial compression. These CFST columns consist of normal and high-strength materials for both steel tube and infilled concrete. In addition to the traditional concrete filled cold-formed steel tubes, spiral welded tubes can be filled with concrete to enhance their performance in terms of stiffness, axial and shear resisting capacity and ductility. Aslani et al. $[10,11]$ carried out a series of tests to investigate the performance of concrete-filled spiral welded steel tubes under 
axial compression. The experimental results demonstrate the excellent mechanical performance of such column types and design recommendations were proposed.

In the present study, spiral welded stainless steel tubes are filled with concrete. A non-linear finite element model based on Abaqus, which incorporates initial imperfections and residual stress, was developed to predict the axial load behaviour of hollow and concrete-filled spiral welded stainless steel tubes. With the developed finite element model, initial stiffness, axial compressive capacity and ductility of the concrete-filled stainless steel tubes under axial compression was evaluated.

\section{Finite element modeling}

As experimental studies on concrete-filled spiral welded stainless steel tubes are expensive and time-consuming, it is necessary to conduct extensive numerical simulation for such columns before the commencement of the experimental work. In this study, the commercial program Abaqus was used to develop an accurate finite element model for predicting the behaviour of concrete-filled spiral welded stainless steel tubes under axial compression. For the purposes of accurate analysis, element type, element mesh, boundary condition, steel tube-concrete interface, material properties for the steel tube and the confined concrete, initial imperfections and residual stresses must all be considered.

\subsection{Element type, mesh size, contact and boundary conditions}

Spiral welded stainless steel tubes and confined concrete are modelled with eight-node brick elements with three translation degrees of freedom at each node (C3D8R). Moreover, according to the mesh sensitivity study, the rational mesh size for steel tubes and in-filled concrete is determined to be $L / 25$, with $L$ representing the length of the column.

As suggested by Li et al. [12], surface-tosurface contact is used to model the interaction between the steel tube and the in-filled concrete. A coefficient of friction between the steel tube and concrete is taken as 0.6. In addition, fixed boundary conditions were applied to the bottom ends of the columns. Furthermore, specimens in this study are loaded under displacement control, which can facilitate the capture of descending branch of the axial load-strain curve [13].

\subsection{Material property for stainless steel}

Stainless steel material properties specified in Abaqus included the elastic and plastic behaviours. For the elastic behaviour, Young's modulus of steel $\left(E_{0}\right)$ and Poisson's ratio $\left(v_{\mathrm{s}}\right)$ are taken as $170,000 \mathrm{MPa}$ and 0.3 , respectively. In terms of the plastic behaviour, the stress-strain relationship is of a "roundhouse" type. As suggested by Tao et al. [14] and Rasmussen [15], two Ramberg-Osgood curves are utilized to describe the behaviour of stainless steel:

$\varepsilon=\frac{\sigma}{E_{0}}+0.002\left(\frac{\sigma}{\sigma_{0.2}}\right)^{n}, \quad \sigma \leq \sigma_{0.2}$

in which $\sigma_{0.2}$ is the $0.2 \%$ proof stress, $n$ is the strain-hardening exponent determined by $\sigma_{0.2}$ and the $0.01 \%$ proof stress $\sigma_{0.01}$, as shown in Eq. (2):

$n=\frac{\ln (20)}{\ln \left(\sigma_{0.2} / \sigma_{0.01}\right)}$

For the stress-strain curve beyond the $0.2 \%$ proof stress, a new expression based on Ramberg-Osgood relationship is used (Eq. 3). A typical stress-strain curve for stainless steel is presented in Fig. 1.

$\varepsilon=\frac{\sigma-\sigma_{0.2}}{E_{0.2}}+\varepsilon_{u}\left(\frac{\sigma-\sigma_{0.2}}{\sigma_{u}-\sigma_{0.2}}\right)^{m}+\varepsilon_{0.2}, \sigma>\sigma_{0.2}$

in which

$E_{0.2}=\frac{E_{0}}{1+0.002 n / e}$

$e=\frac{\sigma_{0.2}}{E_{0}}$

$\sigma_{u}=\frac{\sigma_{0.2}(1-0.0375(n-5))}{0.2+185 e}$

$\varepsilon_{u}=1-\frac{\sigma_{0.2}}{\sigma_{u}}$

$m=1+3.5 \frac{\sigma_{0.2}}{\sigma_{u}}$

$\varepsilon_{0.2}=\frac{\sigma_{0.2}}{E_{0}}+0.002$

\subsection{Material properties for confined concrete}

For a CFST column under axial compression, the infilled concrete expands laterally and is confined by the steel tube. This confinement is passive in nature and can increase the strength and ductility of the concrete. Furthermore, the 


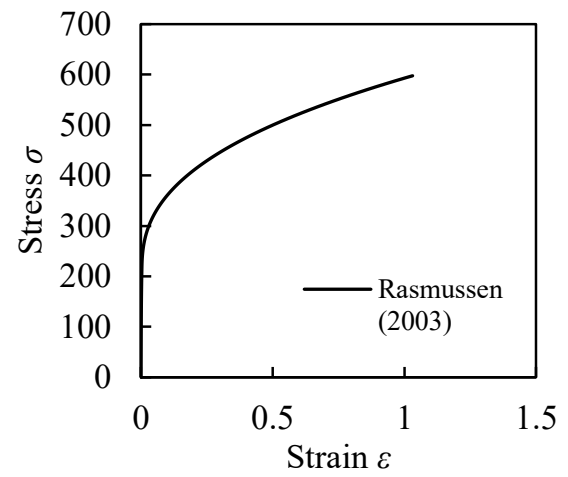

Fig. 1. Typical stress-strain curve for stainless steel

confinement effect depends on the diameter-tothickness ratio of the steel tube and material properties. In this FE analysis, the damage plasticity model defined by Abaqus is used. The damage plasticity model allows a uniaxial compression stress-strain curve, tensile fracture energy and other parameters to be input.

Fig. 2 depicts the confined concrete model proposed by [14]. In the initial stage, there is little interaction between the steel tube and confined concrete. Therefore, the ascending branch of the stress-strain curve of unconfined concrete is appropriate to be used until the peak strength $\left(f^{\prime} \mathrm{c}\right)$ is reached. The following equations are used to describe this curve:

$\frac{\sigma_{c}}{f_{c}^{\prime}}=\frac{A X+B X^{2}}{1+(A-2) X+(B+1) X^{2}}, 0<\varepsilon \leq \varepsilon_{\mathrm{c} 0}$

$X=\frac{\varepsilon}{\varepsilon_{c 0}}$

$A=\frac{E_{c} \varepsilon_{c 0}}{f_{c}^{\prime}}$

$B=\frac{(A-1)^{2}}{0.55}-1$

$\varepsilon_{c 0}=0.00076+\sqrt{\left(0.626 f_{c}^{\prime}-4.33\right) \times 10^{-7}}$

After that, a plateau part is incorporated to simulate the increased strain from confinement effects. Eqs. (15) to (17) are used.

$\frac{\varepsilon_{c c}}{\varepsilon_{c 0}}=e^{k}$

$k=\left(2.9224-0.00367 f_{c}^{\prime}\right)\left(\frac{f_{B}}{f_{c}^{\prime}}\right)^{0.3124+0.002 f_{c}^{\prime}}$

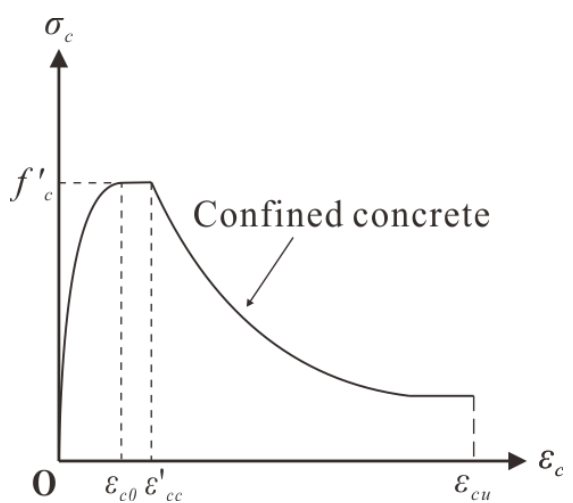

Fig. 2. Stress-strain curve for confined concrete

$f_{B}=\frac{0.25\left(1+0.027 f_{y}\right) e^{\frac{-0.02 \sqrt{B^{2}+D^{2}}}{t}}}{1+1.6 e^{-10}\left(f_{c}^{\prime}\right)^{4.8}}$

In the descending branch, a softening portion with increased ductility due to confinement is considered. Eqs. (16) to (20) are used to describe this behaviour:

$$
\begin{aligned}
& \sigma_{c}=f_{r}+\left(f_{c}^{\prime}-f_{r}\right) \exp \left[-\left(\frac{\varepsilon-\varepsilon_{c c}}{\alpha}\right)^{\beta}\right] \quad \varepsilon \geq \varepsilon_{c c} \\
& f_{r}=0.1 f_{c}^{\prime} \\
& \alpha=0.005+0.0075 \xi_{c} \\
& \beta=0.92 \\
& \xi_{c}=\frac{A_{s} f_{y}}{A_{c} f_{c}^{\prime}}
\end{aligned}
$$

As suggested by ACI [16], the tensile behaviour of the confined concrete is assumed to be linear until the tensile strength is reached, which is taken as $0.56\left(f_{\mathrm{c}}^{\prime}\right)^{0.5}$. Beyond this failure stress, the tensile response is represented by fracture energy $\left(G_{\mathrm{F}}\right)$. According to FIP [17], fracture energy can be calculated through the following equation:

$$
G_{F}=\left(0.0469 d^{2}{ }_{\text {max }}-0.5 d_{\text {max }}+26\right)\left(\frac{f_{c}^{\prime}}{10}\right)^{0.7}
$$

\subsection{Configuration of finite element model}

An example of the finite element model for the concrete-filled spiral welded stainless steel tube can be seen in Fig. 3. For the developed model, the spiral welding has been modelled based on the actual measurement of the welding and specimen. With this detail included, the high-stress of the stainless steel tubes under compression will distribute along the welding in 


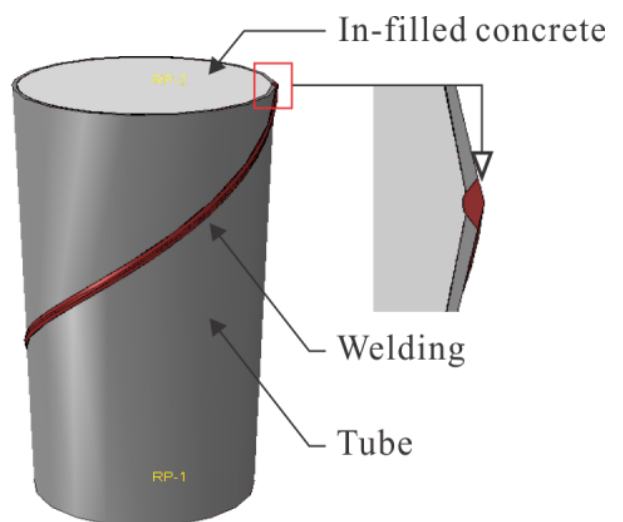

Fig. 3. Configuration of finite element model

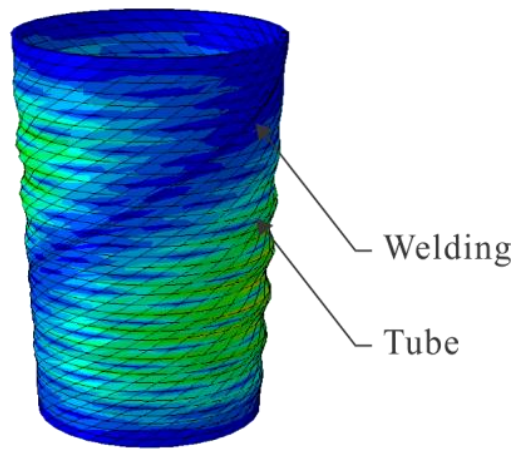

Initial imperfection shape

Fig. 4. Initial imperfection of the hollow spiral welded tube

a helical form. The initial imperfection model has been carried out and shown in Fig. 4, which can demonstrate the effects of helical welding on the stress distribution of such columns.

\section{Parametric study}

With the developed finite element models, a series of parametric studies in terms of the concrete compressive strength, depth-tothickness ratio and specimen slenderness were performed to investigate the influence of these parameters on the structural behaviour of the concrete-filled spiral welded stainless steel tubes under axial compression. Table 1 shows the

Table 1. Parameters considered for parametric study.

\begin{tabular}{ccccc}
\hline Specimen & $\boldsymbol{D}$ & $\boldsymbol{t}$ & $\boldsymbol{f}^{\prime} \mathbf{c}$ & $\boldsymbol{\lambda}$ \\
\hline C-1 & 100 & 2 & 20 & 300 \\
C-2 & 100 & 2 & 30 & 300 \\
C-3 & 100 & 2 & 40 & 300 \\
C-4 & 100 & 2 & 50 & 300 \\
C-5 & 100 & 3 & 50 & 300 \\
C-6 & 100 & 4 & 50 & 300 \\
C-7 & 100 & 5 & 50 & 300 \\
C-8 & 100 & 2 & 50 & 600 \\
C-9 & 100 & 2 & 50 & 800 \\
\hline
\end{tabular}

different parameters and specimens considered for the finite element analysis.

\subsection{Effects of concrete compressive strength}

Fig. 5 presents the effects of the concrete compressive strengths on the axial loaddisplacement curves for the concrete-filled spiral welded stainless steel tubes under axial compression. The specimens C- 1 to C-5 in Table 1 are included in the analysis. It can be observed from Fig. 5 that the initial stiffness and ultimate axial strengths of the concrete-filled spiral welded stainless steel tubes increases with an increase in the concrete compressive strength. However, the use of high strength concrete reduces the ductility of this type of composite column, which is mainly due to the brittle failure of the in-filled concrete.

\subsection{Effects of $D / t$ ratio}

Fig. 6 depicts the effects of depth-tothickness ratio on the axial load-displacement curves for Specimens C-4 to C-7. The material and geometric properties for these specimens are

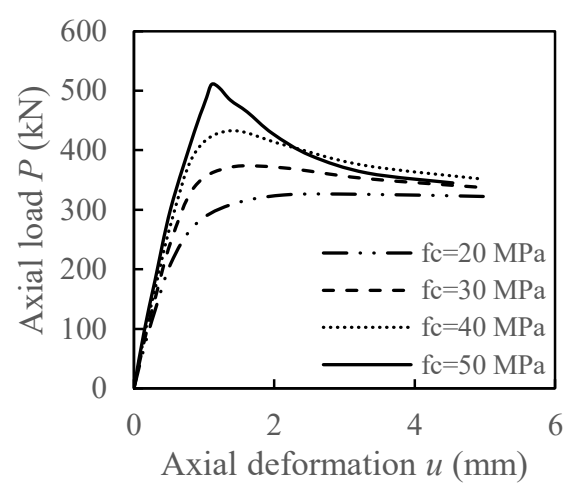

Fig. 5. Effects of concrete compressive strength on the load-displacement curves

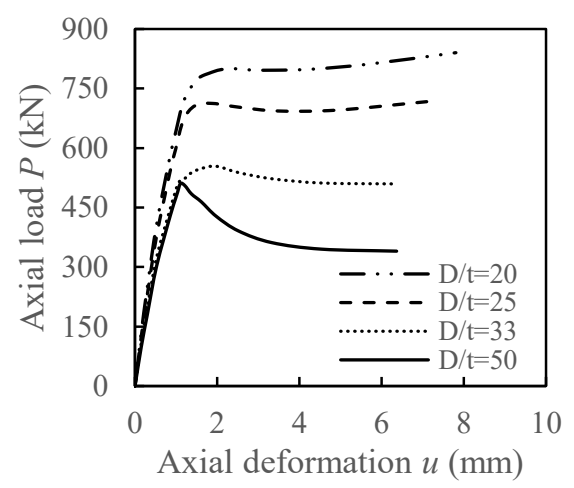

Fig. 6. Effects of $D / t$ ratio on the loaddisplacement curves 
given in Table 1. It is noted from Fig. 6 that the initial stiffness and ultimate axial strength of the concrete-filled spiral welded stainless steel tubes decreases with an increase in depth-to-thickness ratio of the tube section. The ductility of the composite column improves with a decrease in the depth-to-thickness ratio. These phenomenon are to be expected as the lower $D / t$ ratio indicates more steel contribution ratio of the section; consequently more confinement effects will be provided by the stainless steel tube.

\subsection{Effects of slenderness}

Fig. 7 depicts the effects of specimen slenderness on the axial load-displacement curves for Specimens C-4 and C-8 to C-9. It can be seen from Fig. 7 that the ductility, initial stiffness and ultimate strength of the concretefilled spiral welded stainless steel tubes increase with a decrease in the specimen slenderness.

\section{Comparison of ultimate strength with FEM and design codes}

\subsection{Comparison with design codes}

The ultimate axial load capacity from fintite element analysis $N_{\mathrm{M}}$ for concrete-filled stainless spiral welded tubes were compared with the predictions of axial load capacity by using the Eurocode 4 (EC4) [18] and Australian Standards AS/NZS2327 [19]. The comparison results are presented in Table 2. The mean value for $N_{\mathrm{M}} / N_{\mathrm{EC} 4}$ and $N_{\mathrm{M}} / N_{\mathrm{AS} / \mathrm{NZS} 2327}$ is 1.07 and 1.39 , respectively. These results illustrate that the developed finite element models for composite circular columns produced similar predictions with that of EC4. Owing to the reduction factors for structural steel and concrete, which were adopted by AS/NZS2327, the axial load capacity predicted by Australian code is conservative.

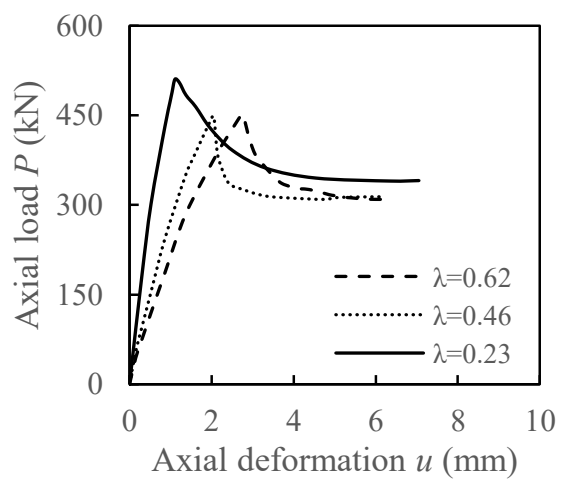

Fig. 7. Effects of slenderness on the loaddisplacement curves
Table 2. Comparison of the load capacity between finite element model and design code.

\begin{tabular}{cccccc}
\hline $\begin{array}{c}\text { Speci } \\
\text { mens }\end{array}$ & $\boldsymbol{N}_{\mathbf{M}}$ & $\boldsymbol{N}_{\mathbf{E C 4} 4}$ & $\begin{array}{c}\boldsymbol{N}_{\text {AS/NZS2 }} \\
\mathbf{3 2 7}\end{array}$ & $\begin{array}{c}\boldsymbol{N}_{\mathbf{M}} / \\
\boldsymbol{N}_{\mathbf{E C 4}}\end{array}$ & $\begin{array}{c}\boldsymbol{N}_{\mathbf{M}} / \\
\boldsymbol{N}_{\text {AS }} \\
\text { NZS2327 }\end{array}$ \\
\hline $\mathrm{C}-1$ & 325 & 283 & 239 & 1.15 & 1.36 \\
$\mathrm{C}-2$ & 371 & 353 & 282 & 1.05 & 1.32 \\
$\mathrm{C}-3$ & 433 & 422 & 326 & 1.03 & 1.33 \\
$\mathrm{C}-4$ & 510 & 492 & 368 & 1.04 & 1.39 \\
$\mathrm{C}-5$ & 554 & 543 & 425 & 1.02 & 1.30 \\
$\mathrm{C}-6$ & 711 & 690 & 479 & 1.03 & 1.46 \\
$\mathrm{C}-7$ & 840 & 728 & 532 & 1.15 & 1.58 \\
$\mathrm{C}-8$ & 449 & 432 & 332 & 1.04 & 1.35 \\
$\mathrm{C}-9$ & 440 & 390 & 320 & 1.13 & 1.38 \\
Mean & & & & 1.07 & 1.39 \\
\hline
\end{tabular}

\subsection{Comparison with SWT with mild steel}

Aslani et al. [10] carried out a series of experimental tests on concrete-filled spiral welded tubes (SWT) and longitudinal welded tubes (LWT) with normal mild steel. A similar experimental design was performed, where the specimens possessed similar geometric properties as the specimen C-4 shown in Table 1. Comparison of the behaviour between the concrete-filled tubes with normal mild steel and stainless steel was conducted.

Comparison in terms of the load-deformation curves between various specimens were plotted in Fig. 8, it can be seen that the initial stiffness of these specimens are similar. However, the post-peak behaviour of specimen C-4 is less desired, compared to the counterparts CLWT102 and C-SWT102, which were either longitudinally welded or spirally welded with mild steel strips. In addition to the initial stiffness and ductility performance, comparisons regarding the ultimate axial load bearing capacity between these specimens was also carried out. As can be seen in Table 3, the ultimate axial strength of the specimens is

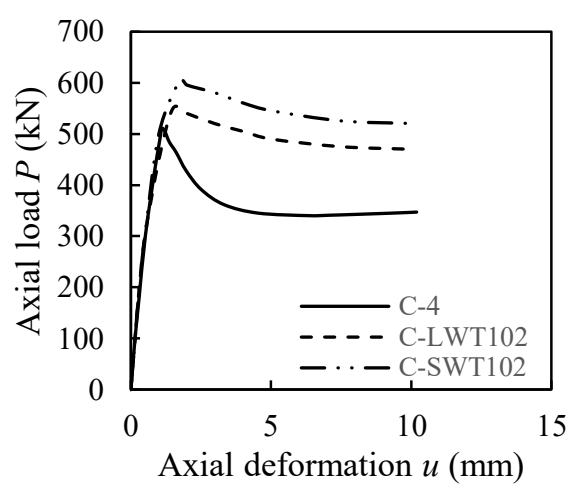

Fig. 8. Comparison of load-deformation curves between various specimens 
Table 3. Comparison of the load capacity between various specimens.

\begin{tabular}{cccccc}
\hline Specimens & $\boldsymbol{D} \times \boldsymbol{t} \times \boldsymbol{L}$ & $\boldsymbol{f}_{\mathbf{c}}$ & $\boldsymbol{f}_{\mathbf{y}}$ & $\boldsymbol{N}_{\mathbf{u}}$ & $\boldsymbol{N}_{\mathbf{E C} 4}$ \\
\hline C-4 & $100 \times 2 \times 300$ & 50 & 220 & 510 & 492 \\
C-SWT102 & $103 \times 2 \times 300$ & 50 & 288 & 609 & 597 \\
C-LWT102 & $101 \times 2 \times 300$ & 50 & 277 & 555 & 572 \\
\hline
\end{tabular}

different, which is to be expected.

The enhancement of the axial load capacity was mainly attributed to the higher yield strength from the specimens C-LWT102 and C-SWT102. Nevertheless, considering the engineering application with existing design provisions, it can also be found that the current codes of practice are accurate for the strength predictions for such types of structues.

\section{Conclusions}

Axially loaded behaviour of concrete-filled spiral welded stainless steel tubes have been investigated herein with the finite element model. The proposed finite element model provides an efficient method for structural analysis in order to develop design guidance for this application of composite structures.

A parametric study of different variables was performed to investigate the effects of pertinent parameters on the structural behaviour of the concrete-filled spiral welded stainless steel tubes. From the analysis results, it can be concluded that:

(i) An increase in the concrete compressive strength causes an increase in the axial loading capacity and initial stiffness of this column. But the ductility performance of this column is negatively affected.

(ii) The decrease of the depth-to-thickness ratio of the steel tube will increase the axial compressive capacity, initial stiffness and the ductility performance significantly, providing the concrete compressive strength and steel yield strength is fixed.

(iii) The ductility, initial stiffness and ultimate strength of the concrete-filled spiral welded stainless steel tubes increase with a decrease in the column relative slenderness ratio.

(iv) The axial load capacities of a series of concrete-filled spiral welded stainless steel tubes obtained from finite element model were compared with those based on existing design codes. It was found that the prediction values from Eurocode 4 were close to the results from finite element analysis. In addition, the Australian Standards AS/NZS2327 leads to more conservative results due to the adoption of reduction factors for structural steel and concrete under axial compression.

(v) Finite element modeling was compared with existing test specimens, which possessed similar geometric and material properties. The comparison results indicated that the ultimate strength and initial stiffness of the specimens are similar, however, the post-peak behaviour of concrete-filled spiral welded stainless steel tubes are less desired.

\section{References}

[1] Richard L. Spiral Welded Pipe Piles for Structures in Southeastern Louisiana (Master of Science Thesis) University of New Orleans, 2004.

[2] Brensing KH, Sommer B. Steel tube and pipe manufacturing processes; 2003.

[3] Sadowski A, Rotter J, Reinke T, Ummenhofer T. Analysis of variance of tensile tests from spiral welded carbon steel tubes. Construction and Building Materials 2015; 75: 208-212.

[4] Xiao Y, Zhang ZX, Hu JH, Kunnath SK, Guo PX. Seismic behaviour of CFT column and steel pile footings. Journal of Bridge Engineering 2011; 16(5): 575-586.

[5] Uy B. Strength of concrete filled steel box columns incorporating local buckling. Journal of Structural Engineering 2000; 126(3): 341-352.

[6] Uy B. Strength of short concrete filled highstrength steel box columns. Journal of Constructional Steel Research 2001; 57: 113-34.

[7] Han LH. Tests on stub columns of concrete-filled RHS sections. Journal of Constructional Steel Research 2002; 28(3): 353-372.

[8] Giakoumelis G, Lam D. Axial capacity of circular concrete-filled tube columns. Journal of Constructional Steel Research 2004; 60(7): 1049-1068.

[9] Liew JYR, Xiong DX. Effect of preload on the axial capacity of concrete-filled composite columns. Journal of Constructional Steel Research 2001; 65(3): 709-722.

[10] Aslani F, Uy B, Hur J, Carino P. Behaviour and design of hollow and concrete-filled spiral welded steel tube columns subjected to axial compression. Journal of Constructional Steel Research 2017; 128: 261-288.

[11] Aslani F, Uy B, Hicks SJ, Kang WH. Spiral welded tubes-imperfections, residual stress, and buckling characteristics. Eigth International 
Conference on Advances in Steel Structures, Lisbon, Portugal; 2015.

[12]Li D, Uy B, Aslani F, Patel V. Behaviour and design of demountable CFST column-column connections under tensión. Journal of Constructional Steel Research 2017; 138: 761773.

[13] Li D, Uy B, Patel V, Aslani F. Behaviour and design of demountable CFST column-column connections subjected to compression. Journal of Constructional Steel Research 2018; 141: 262274.

[14] Tao Z, Uy B, Liao FY, Han LH. Nonlinear analysis of concrete-filled square stainless Steel stub columns under axial compression. Journal of Constructional Steel Research 2013; 89: 121 131.

[15] Rasmussen KJR. Full-range stress-strain curves for stainless steel alloys. Journal of Constructional Steel Research 2003; 59(1): 47 61.

[16]ACI-318. Building code requirements for reinforced concrete. Detroit, MI: ACI; 2008.

[17]FIP. CEB-FIP Model Code 1990. Thomas Telford Ltd., London; 1993.

[18] Eurocode 4, Design of Composite Steel and Concrete Structures, Part 1.1: General Rules and Rules for Building. BS EN 1994-1-1; 2004.

[19] Standards Australia AS/NZS2327-2017, Composite Structures - composite steel-concrete construction in buildings; 2017. 